\title{
Effectiveness of Module Based Learning (MBL) Regarding Facility Based New born Care (FBNC) in Terms of Knowledge and Practices Among Nursing Students
}

\author{
Minal Kumari ${ }^{1 *}$, Yogesh Kumar ${ }^{2}$ and Parvinder Kaur ${ }^{3}$ \\ ${ }^{1}$ M.Sc. Nursing in Child Health Nursing Department Maharishi Markandeshwar College of Nursing MMU Mullana, Haryana, India \\ ${ }^{2}$ Professor in Child Health Nursing, Maharishi Markandeshwar College of Nursing MMU Mullana, Haryana, India \\ ${ }^{3}$ Associate Professor in Child Health Nursing, Maharishi Markandeshwar College of Nursing MMU Mullana, Haryana, India \\ *Corresponding Author: Minal Kumari, M.Sc. Nursing in Child Health Nursing Department Maharishi Markandeshwar College of Nursing \\ MMU Mullana, Haryana, India.
}

Received: September 13, 2019; Published: October 11, 2019

DOI: 10.31080/ASNH.2019.03.0501

\begin{abstract}
Background: Mobile Applications are being developed at a rapid speed and are intensively used by students. It can help to achieve better performance in organizing, managing, and monitoring classroom activities.

Aims and objectives: Present study aimed to assess and compare the knowledge and practice regarding FBNC among nursing students in MBL group and MABL group before and after the administration of MBL and MABL. The conceptual framework of the study was based on CIPP model by Stuff lebeam.

Methods: A Quantitative research approach with quasi-experimental and non-equivalent control group pre-test post-test design. The study was conducted at two nursing colleges of Ambala, Haryana. A total of 70 B.Sc. Nursing 3rd Year students, randomly allocated to 2 groups i.e. 35 in MBL and 35 in MABL. The tool used for the study consisted of structured knowledge questionnaire and observational check list was used to assess knowledge and practices by OSCE method of nursing students regarding FBNC. Data collection was done in January, 2017. The obtained data was analysed and interpreted in terms of objectives and research.

Results: Findings of the study indicate that revealed that mean post- test knowledge and practices score in MBL group (21.4 \pm 0.89 ) and in MABL group $(22.4 \pm 0.54)$ was significantly higher than pre-test knowledge score in MBL group (14.6 \pm 15.0$)$ and in MABL group (16.2 \pm 17.0 ). Also, the mean post-test practice score in MBL group (38.1 \pm 1.91 ) and in MABL group (38.9 \pm 1.20$)$ was significantly higher than pre-test practice score in MBL $(20.4 \pm 3.70)$ as well as in MABL group $(20.5 \pm 4.26)$. Mild positive significant relationship ( $\mathrm{r}=0.03$ ) was found between post test score of knowledge and practices.

Conclusion: MABL was more effective in developing the practices of nursing students regarding FBNC than MBL.

Keywords: Effectiveness; Module Based Learning (MBL); Mobile Application Based Learning (MABL); Knowledge; Practices; Nursing Students
\end{abstract}

\section{Introduction}

Newborn constitute the foundation of life. The neonate period refers from birth to 28 days of life. First week of life is the crucial period in the life of an infant [1]. Care provides during this period is critical in helping to prevent complications and ensuring intact survival. The four essential and basic needs of all newborns are: Warmth, Normal Breathing, Mothers milk and Protection, indicate that a baby's survival is totally dependent upon its mother and other care givers. So it is important to provide proper care to all the neonates immediately after birth [2].

Preventable morbidities such as hypothermia, asphyxia, neonatal sepsis, diarrhea, preterm, congenital, tetanus, pneumonia and respiratory distress continue to be the main cause of mortality in the neonatal period. In India, 26 million babies are born every year and 940,000 babies die before one month of life [3].
According to Ekwochi U., et al. the place of birth is not the problem but the immediate care babies receive needs to be improved. Whereas facility newborn care is viewed as necessary in reducing neonatal deaths, factors that have been identified in enabling this to occur included regionalization of perinatal care, strengthening of lower level units, in-born status and adequate nursing staff [4].

Mobile application used by health care professionals (HCPs) has transformed many aspects of clinical practice. Mobile devices have become common place in health care settings, leading to rapid growth in the development of medical software applications (apps) for these platforms [5]. A nurse's responsibility requires safe and effective care within constantly evolving health care systems. Since skills and knowledge are learned through experience, constant practice and good instructions [6]. 
An experimental study was conducted to assess the knowledge and skill scores of pediatricians working in SNCUs in the state of Tamil Nadu, The study aim to Efficacy and acceptability of an "App on sick newborn care" in physicians from newborn units India $(n=32)$ were assessed by 25 multiple choice questions (MCQs) and by five Objective Structured Clinical Examination (OSCE) skill stations. Training was conducted in a single-day workshop using the app on four modules. The mean knowledge scores [19.4 (2.6) vs. 10.7 (3.2); maximum marks (MM) 25, mean difference 8.7 (95 \% CI 7.6 to 9.9)], and the composite mean skill scores [55.2 (5.8) and 42 (6.2), MM 75, mean difference 13.2 (95\% CI 10.4 to 15.9)] improved after training [7].

\section{Materials and Methods}

This study was conducted in a nursing college with the approval of ethical committee of the university. A written and informed consent was obtained from the students. A Quantitative research approach with Non-Equivalent Control Group Pre-test Post-test design was used. Nursing students were selected as a sample with inclusion criteria that nursing students present at the time of data collection. Total 70 B.Sc. nursing $3^{\text {rd }}$ year students, who were selected by using Convenience Sampling and to prevent contamination nursing students randomly allocated into 2 groups i.e. 35 in MBL from M.M. College of Nursing Mullana, Haryana and 35 in MABL from M.M. Institute of Nursing Mullana, Haryana. Structured knowledge questionnaire and Structured observational check list was used to assess knowledge and practices by OSCE method of nursing students regarding FBNC. The calculated Cronbach's reliability value for the scale in OSCE was 0.84 and Kuder Richardson -20 used to check the internal consistency of a structured knowledge questionnaire which was 0.78 .

In MBL group, on $1^{\text {st }}$ day, Pre-test of knowledge and practices of all nursing students regarding FBNC was assessed. On 2nd day administration of Module-Based teaching on selected topics of module, duration of teaching was 2 hours while demonstration took 2 hours. On $15^{\text {th }}$ day Post-test of knowledge and practices of all nursing students regarding FBNC was assessed.

In MABL group, on $1^{\text {st }}$ day Pre- assessment of knowledge and practices of all nursing students regarding FBNC was assessed. On $2^{\text {nd }}$ day administration of Mobile Application Based teaching on selected topics with the help of videos, posters and modules duration on mobile based teaching for modules 2 hours, posters 15 minutes and for videos 75 minutes. On $15^{\text {th }}$ day post assessment of Knowledge and practices of all nursing students regarding FBNC was assessed.

\section{Results}

The personal characteristics of both the profiles were comparable. The computed chi square value for the selected variables in MBL and MABL group for age (4.92), education (14.1) MBL and MABL group for age (4.92), education (14.1) were found to be non siblings from nursing profession (0.40), father's education(19.2) and mother's were found to be non significant at 0.05 level of significance. Hence it was revealed from the findings that MBL and MABL group were homogenous with regard to these selected variables except religion which was statistically significant at 0.05 level of significance The mean, median, standard deviation, standard error of mean and " $\mathrm{t}$ " value were calculated within the group and between the group as per standard criteria (Table 1 and 2). The calculated " $\mathrm{t}$ " value within group for both the groups were 25.38 and 22.35 in knowledge score (table 1) whereas 15.4 and 17.9 in practices (table 2) which is statistically significant at 0.05 level of significance. The calculated " $\mathrm{t}$ " value between group 11.68 in practices (significant at 0.05 level) and 1.86 (non significant at 0.05 level). Cross over concludes practices had an influence for knowledge but no influence of knowledge on practices (Table 3).

\begin{tabular}{|c|c|c|c|c|c|c|c|}
\hline \multicolumn{2}{|c|}{ Group } & Mean & M & SD & SE & 't' & p \\
\hline $\begin{array}{l}\text { MBL } \\
(n=35)\end{array}$ & $\begin{array}{l}\text { Pre test } \\
\text { Post test }\end{array}$ & $\begin{array}{l}20.5 \\
38.1\end{array}$ & 17.6 & 2.35 & .695 & 25.38 & $0.001 *$ \\
\hline $\begin{array}{l}\text { MABL } \\
(n=35)\end{array}$ & $\begin{array}{l}\text { Pre test } \\
\text { Post test }\end{array}$ & 38.9 & 14.8 & 2.5 & .665 & 22.35 & $0.001 *$ \\
\hline
\end{tabular}

Table 1: Mean, Mean difference, standard deviation of difference, standard error of mean difference and ' $t$ ' value between MBL and MABL of knowledge score $\mathrm{N}=70$.

$$
\begin{gathered}
' \mathrm{t}^{\prime}(68)=2.00(\mathrm{p} \leq 0.05) \text { NS- not significant }(\mathrm{p}>0.05), \\
*_{\text {- significant }(\mathrm{p}<0.05) .}
\end{gathered}
$$

Table 1, 2 and 3 concludes that there was a significant difference in mean knowledge and practices within and between and within both the groups. Hence research hypothesis was accepted and null hypothesis was rejected. Area wise knowledge and practices analysis on MBL and MABL groups are described as per the standard criteria (Table 4 and 5). 
Effectiveness of Module Based Learning (MBL) Regarding Facility Based New born Care (FBNC) in Terms of Knowledge and Practices Among Nursing Students

\begin{tabular}{|l|c|c|c|c|c|c|}
\hline \multicolumn{1}{|c|}{ Group } & Mean & $\mathbf{M}_{\mathrm{D}}$ & $\mathbf{S D}_{\mathrm{D}}$ & $\mathbf{S E}_{\mathrm{MD}}$ & $\begin{array}{c}\text { 't' } \\
\text { value }\end{array}$ & $\begin{array}{c}\mathbf{P} \\
\text { value }\end{array}$ \\
\hline $\begin{array}{l}\text { MBL group } \\
\text { (n=35) }\end{array}$ & 43.7 & 25.5 & 7.01 & 1.65 & 15.4 & $0.001^{*}$ \\
$\begin{array}{l}\text { Pre test } \\
\text { Post test }\end{array}$ & 69.2 & & & & & \\
\hline $\begin{array}{l}\text { MABL group } \\
\text { (n=35) } \\
\text { Pre test } \\
\text { Post test }\end{array}$ & 76.6 & 30.9 & 6.98 & 1.71 & 17.9 & $0.001^{*}$ \\
\hline
\end{tabular}

Table 2: Mean, Mean difference, standard deviation of difference, standard error of mean difference and ' $\mathrm{t}$ ' value between MBL an MABL in practice score $\mathrm{N}=70$.

*Significant $(\mathrm{p} \leq 0.05)$ Ns Non Significant $(\mathrm{p} \geq 0.05)$.

\begin{tabular}{|l|c|c|c|c|c|c|}
\hline Variables & Group & Mean & $\mathbf{M}_{\mathbf{D}}$ & $\mathbf{S E}_{\mathrm{MD}}$ & $\begin{array}{c}\text { 't' } \\
\text { value }\end{array}$ & $\begin{array}{c}\mathbf{p} \\
\text { value }\end{array}$ \\
\hline Knowledge & $\begin{array}{c}\text { Post-test } \\
(\mathrm{n}=35) \mathrm{MBL} \\
\text { group } \\
\text { Practices }\end{array}$ & 38.1 & 0.8 & 0.38 & 1.86 & $0.06^{\mathrm{NS}}$ \\
& $\begin{array}{c}\text { MABL group } \\
\text { Post-test } \\
\text { (n=35) MBL } \\
\text { group } \\
\text { MABL group }\end{array}$ & 77.5 & 89.2 & 0.70 & 11.68 & $0.001^{*}$ \\
\hline
\end{tabular}

Table 3: Mean, Mean difference, standard deviation of difference, standard error of mean difference and ' $\mathrm{t}$ ' value between MABL and MABL group. $\mathrm{N}=70$.

$' t '(68)=2.00(p \leq 0.05)$ NS- not significant $(p>0.05)$, *-significant $(\mathrm{p}<0.05)$.

\begin{tabular}{|c|c|c|c|c|c|c|c|c|}
\hline Sr.no & Areas & Pre test mean & Post test mean & $\mathbf{M}$ & $\mathbf{S D}_{\mathrm{D}}$ & $\mathrm{SE}_{\mathrm{MD}}$ & 't' value & p value \\
\hline \multirow{9}{*}{$\begin{array}{l}1 . \\
2 . \\
3 . \\
4 . \\
5 . \\
6 . \\
7 .\end{array}$} & Module group $(n=35)$ & & & & & & & \\
\hline & Hand Washing & 2.40 & 4.97 & 2.5 & 0.78 & 0.24 & 1.38 & $0.001 *$ \\
\hline & Weighing the Newborn & 2.42 & 5.00 & 2.5 & 1.26 & 0.50 & 7.0 & $0.002^{*}$ \\
\hline & Good attachment signs during Breast Feeding & 2.54 & 4.97 & 2.4 & 0.6 & 0.37 & 0.53 & $0.62^{\mathrm{NS}}$ \\
\hline & Kangaroo Mother Care & 2.57 & 4.97 & 2.4 & 0.87 & 0.40 & 3.50 & $0.025^{\mathrm{NS}}$ \\
\hline & Paladai Feeding & 2.34 & 4.68 & 2.3 & 3.16 & 0.66 & 4.82 & $0.008^{\mathrm{NS}}$ \\
\hline & Oxygen supply By Hood & 2.91 & 4.45 & 1.5 & 3.07 & 0.50 & 1.17 & $0.305^{\mathrm{NS}}$ \\
\hline & Nasogastric intubation & 5.91 & 9.10 & 3.1 & 6.3 & 1.2 & 2.1 & $0.99^{\mathrm{NS}}$ \\
\hline & MOBILE group $(n=35)$ & & & & & & & \\
\hline 1. & Hand Washing & 2.00 & 5.00 & 3 & 0.8 & 0.3 & 7.4 & $0.002^{*}$ \\
\hline 2. & Weighing the Newborn & 2.60 & 5.00 & 2.4 & 1.24 & 0.3 & 10.1 & $0.001^{*}$ \\
\hline 3. & Good attachment signs during Breast Feeding & 3.08 & 5.00 & 1.9 & 0.88 & 0.00 & 7.06 & $0.002^{*}$ \\
\hline 4. & Kangaroo Mother Care & 2.80 & 5.00 & 2.2 & 2.6 & 0.58 & 3.0 & $0.003^{*}$ \\
\hline 5. & Paladai Feeding & 3.51 & 4.88 & 1.23 & 1.3 & 0.58 & 6.51 & $0.003^{*}$ \\
\hline 6 & Oxygen supply By Hood & 3.97 & 4.71 & 1.37 & 1.4 & 0.6 & 1.2 & $0.2^{\mathrm{NS}}$ \\
\hline 7. & Nasogastric intubation and Feeding & 6.1 & 9.36 & 3.2 & 2.5 & 1.15 & 0.69 & $0.58^{\mathrm{NS}}$ \\
\hline
\end{tabular}

Table 4: Area Wise Mean, Mean Difference, Standard Deviation of difference, Standard Error of Mean Difference and ' $t$ ' value of knowledge score $N=70$, ' $t$ ' $(199)=1.98(p \leq 0.05)$ NS- not significant $(p>0.05),{ }^{*}$ - significant $(p<0.05)$.

\begin{tabular}{|l|c|c|c|c|c|c|c|c|}
\hline S.no & Areas & Pre test Mean & Post test Mean & $\mathbf{M}_{\mathbf{D}}$ & $\mathbf{S D}_{\mathbf{D}}$ & $\mathbf{S E}_{\mathbf{M D}}$ & $\mathbf{~} \mathbf{\prime}^{\prime}$ value & $\mathbf{p}$ value \\
\hline & MBL group (n=35) & & & & & & & \\
1. & Hand Washing & 7.74 & 10.54 & 2.8 & 1.0 & 0.44 & 6,708 & $0.003^{*}$ \\
2. & Weighing Newborn & 4.51 & 7.09 & 2.58 & 1.22 & 0.54 & 5.47 & $0.005^{*}$ \\
3. & Good attachment signs & 2.34 & 3.74 & 1.4 & 0.54 & 0.24 & 9.79 & $0.001^{*}$ \\
4. & Kangaroo Mother Care & 4.54 & 8.69 & 4.15 & 0.89 & 0.40 & 8.50 & $0.001^{*}$ \\
5. & Paladai Feeding & 6.74 & 8.86 & 2.12 & 1.14 & 0.50 & 2.746 & $0.052^{\text {NS }}$ \\
6. & Oxygen supply By Hood & 3.86 & 6.91 & 3.05 & 0.89 & 0.40 & 8.5 & $0.001^{*}$ \\
7. & NC intubation and Feeding & 14.0 & 23.46 & 9.46 & 1.2 & 0.50 & 12.78 & $0.001^{*}$ \\
& MaBL group(n=35) & & & & & & & \\
1 & Hand Washing & 7.49 & 11.63 & 4.14 & 1.30 & 0.53 & 7.80 & $0.009^{\text {NS }}$ \\
2. & Weighing Newborn & 4.83 & 7.83 & 3.00 & 0.83 & 0.37 & 7.48 & $0.02^{*}$ \\
3. & Good attachment signs & 2.49 & 4.00 & 1.51 & 1.30 & 0.58 & 8.48 & $0.005^{*}$ \\
4. & Kangaroo Mother Care & 6.11 & 9.43 & 3.32 & 1.64 & 0.73 & 7.07 & $0.002^{*}$ \\
5. & Paladai Feeding & 6.11 & 9.66 & 3.55 & 2.16 & 0.96 & 7.30 & $0.03^{*}$ \\
6. & Oxygen supply by Hood & 4.26 & 7.80 & 3.54 & 1.00 & 0.44 & 9.18 & $0.00^{*}$ \\
7 & NC intubation and Feeding & 15.3 & 27.2 & 11.92 & 2.77 & 1.24 & 15.2 & $0.01^{*}$ \\
\hline
\end{tabular}

Table 5: Area Wise Mean, Mean Difference, Standard Deviation of difference, Standard Error of Mean

Difference and ' $t$ ' value of practice scores $N=70$, ' $t$ ' $(199)=1.98(p \leq 0.05)$ NS- not significant $(p>0.05)$, *- significant $(p<0.05)$. 


\section{Discussion}

In the present study Knowledge in MBL Group, the pre-test group score was in range of 9 - 29, with mean of $20.5 \pm 4.26$ and median of 20 . The post test score showed a range of $33-40$, with mean of $38.1 \pm 1.91$ and median of 39. Similarly MABL Group, the pre-test group score was in range of 18-32, with mean of $24.1 \pm$ 3.70 and median of 23.0. The post test score showed a range of 35 40 , with mean of $38.9 \pm 1.20$ and median of 39 . The pre test scores were significantly higher in MABL Group as compared to pre-test scores of MBL Group. Similarly the post test score were significantly higher in Mobile based Group as compared to post test scores of Module Group The result of the present study had shown that in practices MBL Group, the pre-test group score was in range of 15 61 , with mean of $43.7 \pm 10.5$ and median of 47 . The post test score showed a range of $63-75$, with mean of $69.2 \pm 3.49$ and median of 70 Similarly MABL Group, the pre-test group score was in range of $21-62$, with mean of $46.6 \pm 9.24$ and median of 47 . The post test score showed a range of $71-80$, with mean of $77.5 \pm 2.26$ and median of 78, for comparison using independent $t$ test and were found to be significant i.e. the post test scores were significantly higher as compared to pre-test scores of Mobile based group.

The results are consistent with the study conducted by Deorari Ashok, (2014) pre and post, $12.4 \pm 2.2$ and 19.7 \pm 3.6 ; $\mathrm{P}<0.001$ and composite Objective Structured Clinical Examination scores (32.8 \pm 7.3 vs. $63.7 \pm 7.1 ; \mathrm{P}<0.001$ ) significantly improved after training. The interactive mobile device application 'Apps on sick newborn care' derived students overall satisfaction from the training.

\section{Conclusion}

To put in the nutshell, present study revealed that MABL was more effective in developing the practices of nursing students regarding FBNC than MBL as evaluated by structured knowledge questionnaire and structured checklist by OSCE method.

\section{Acknowledgement}

This is to acknowledge that the above said authors had carried out the research work titled "Assess the effectiveness of Module Based Learning (MBL) regarding Facility Based Newborn Care (FBNC) in terms of knowledge and practices among nursing students." Hence we acknowledge that the above research was original work of authors.

\section{Bibliography}

1. Bridges KM. "Emotional development in early infancy". Child Development (1932): 324-341.

2. Hall dorsdottir S and Karlsdottir SI. "Journeying through labour and delivery: perceptions of women who have given birth". Midwifery 12.2 (1996): 48-61.
3. Lawn JE., et al. "Lancet Neonatal Survival Steering Team. 4 million neonatal deaths: when? Where? Why?". Lancet 365.9462 (2005): 891-900.

4. Maine D. "Monitoring emergency obstetric care: a handbook". World Health Organization (2009).

5. Scrivener Jim. "Learning Teaching. Oxford: Macmillan, 2005". Teacher Learning in Language Teaching. Ed. Freeman, Donald, and Richards, Jack C. New York: Cambridge University Press, (1996).

6. Seltzer K and Bentley T. "The creative age". Demos, London. (1999).

7. Deorari Kumar Ashok., et al. "Efficacy and acceptability of an "App on sick newborn care" in physician". BMC Medical Education 16.84 (2016): 1-8.

\section{Volume 3 Issue 11 November 2019 (C) All rights are reserved by Minal Kumari., et al.}

